\title{
Reseña. César Zamorano Díaz. Escrituras en tránsito. Revistas y redes culturales en América Latina. Editorial Cuarto Propio, 2018.
}

Estudiar y analizar una o varias revistas implica tener presente, de antemano, que son objetos de estudio ricos en información y, a su vez, complicados de abordar debido a su hibridez temática e irregular existencia en el tiempo. En línea con esa variedad temática de las revistas, el libro Escrituras en tránsito. Revistas y redes culturales en América Latina editado por César Zamorano, hace honor a ese bien llamado "deseo de revista" (Beatriz Sarlo), haciéndose cargo de tres ejes temáticos tan fundamentales, como recurrentes, entre las investigaciones sobre estos periódicos: primero, "Diálogos continentales e identidades colectivas"; segundo, "Escrituras políticas. Políticas de la escritura"; tercero, "Campos culturales, corrientes literarias".

En concordancia con el título de este libro y con las tres líneas temáticas que lo organizan, en esta presentación me abocaré a relevar el carácter de red de las revistas y el modo en que dicha cualidad es bien expuesta a lo largo de los 19 artículos que componen este trabajo de calidad y nivel tan excepcional preparado por César Zamorano. 


\section{1. ¿Qué son?}

Las revistas culturales son aquellas publicaciones periódicas, de frecuencia semanal, quincenal, mensual, entre otras, cuya propiedad central es la compatibilización tanto de temáticas pertenecientes a diferentes esferas del acontecer social, como de tipos de géneros discursivos y literarios, así también de variedad de formatos materiales que van desde el colorido magazín, hasta las sobrias revistas literarias. Algo similar sucede con el número de agentes que participan de ella, puesto que no existe un límite ni menos un compromiso de permanencia en los cargos que ocupan o en las columnas que redactan. En términos específicos, podemos afirmar que,

a) La revista es un fenómeno semiótico de orden cultural, antes que literario, político, artístico, etc.; por lo cual son hechos culturales híbridos, difíciles de delimitar desde la perspectiva teórica y metodológica, pues no involucran un solo sistema semiótico.

b) La revista es el resultado del cruce de signos, un conglomerado de elementos disímiles que otorgan significación y configuran a la publicación.

c) Las revistas culturales se subclasifican acorde a sus propias nominaciones, entre ilustradas, artísticas, literarias y literario-políticas. Estas denominaciones responden no sólo a valores estéticos, sino que sociales, como es el caso de las ilustradas, las que mediante dicha mención demarcan el habitus tanto de quienes la producen como de quienes la leen.

\section{Red de revistas culturales}

Correspondiente con la idea de "cohesión sociosemiótica" que alcanzan los agentes, quienes motivados por las necesidades del campo construyen formaciones (Raymond Williams), las revistas culturales también constituyen redes entre las 
mismas, con las cuales mantienen relaciones tanto de concordancia como de discordancia, demarcando así, entre otras cosas, las posiciones que ocupan. Sobre esto versa el trabajo de Lidia María de Abreu Generoso sobre la revista Tricontinental, a la cual entiende como

una modalidad de interneción cultura que busc[ó] cortar con un discurso y ausencia de un debate estético o ideológico, aspirando a ser una presencia inmediata en la intelectualidad. La revista Tricontinental buscó intervenir en la realidad por medio de un discurso elaborado para los movimientos revolucionarios de tres continentes [...]. (55)

Por otro lado, las menciones que se realizan entre revistas, las presentaciones, las mismas polémicas, y la crítica "cruzada" que exponen, forman parte de los discursos que nos permiten considerar que estas publicaciones no son fenómenos aislados del sistema cultural y literario, y menos del conjunto de publicaciones periódicas. Es decir, las revistas se proyectan y, al mismo tiempo, proyectan lo que Alexandra Días Ferras Tedesco señala como "efecto de grupo", idea que a la autora le permite "pensar la circulación de estas obras en cuanto 'difusión de un proyecto intelectual' más allá de desacuerdos o diferencias de tono de las obras que lo componen" (26).

Entender las posiciones que ocupan las revistas dentro del campo cultural a partir de los discursos que las constituyen, no es parte de la información "dada" por ellas, sino que es parte del estudio sistemático que nos permite hipotetizar respecto de esta red. La red que configuran las revistas no pasan por relaciones reales de intercambio personal como los encuentros de los productores que las editan; sino que por los juegos lingüísticos que emprenden, identificables a través de la función metacrítica y la función postulativa, entendida esta última como las referencias que realizan las revistas respecto del estado general de la publicación de esta clase de periódicos. A propósito de las revistas político- culturales, la autora Martina Garategaray indica que éstas “permiten una interesante comprensión de los cambios 
políticos e ideológicos sobre los que se propone reflexionar lsa nueva historia de las ideas , y son una entrada extremadamente auspiciosa para analizar un momento de quiebre y crisis como fueron las transiciones a la democracia en Argentina y América Latina" (116).

En otro ámbito, si nos preocupáramos de los encuentros personales que gracias a las revistas se entablan, dejaríamos a las publicaciones en el lugar de en medio. Sin embargo, cuando volvemos la mirada sobre los textos, otorgamos protagonismo al objeto de estudio pues es relevante estudiar los modos en que se reconstruyen, discuten, y "juegan" incorporando nuevos saberes a los relatos preexistentes. Marina Popea, en su artículo "Matices de la postvanguardia. Traducción de poesía en Orígenes (1944-1956)", comenta que "mediante el inventario y el análisis de las traducciones publicadas en Orígenes, observamos que hay en la revista no una, sino dos líneas coexistentes (en las que incluso aparecen varias tendencias distintas". (69) Gracias a la convivencia de estas dos líneas, la revista Orígenes "edific[ó] importantes puentes tanto transatlánticos como hemisféricos [...]" (67).

Respecto del problema de la "red" de revistas, Roland Barthes se vuelve indispensable para comprender esta noción y la de texto:

¿Qué es, pues, el texto? No daré una definición, porque esto implicaría recaer en el significado.

El texto, en el sentido moderno, actual, que intentamos dar a esta palabra, se distingue fundamentalmente de la obra literaria porque:

No es un producto estético ni una práctica significante;

No es una estructura, es una estructuración;

No es un objeto, es un trabajo y un juego;

No es un conjunto de signos cerrados, dotados de un sentido que se trataría de encontrar, es un volumen de huellas en trance de desplazamiento. ( $E l$ Grado Cero, 12-13) 
Cada uno de los elementos y recursos visuales, formales, etc., que forman a las revistas, corresponden a las unidades que le otorgan sentido y significación a esta clase de producción cultural, la revista, a la que no llamamos producto puesto que, al igual que la definición que Barthes da de texto, ésta no es cerrada ni tampoco está construida a partir de términos unívocos. Por el contrario, desde el título hasta los agentes que participan de ella aportan significación a estas publicaciones, quienes se constituirán en configuradores del habitus de las revistas. Es en esta perspectiva que Claudia Gilman propone lo siguiente: "Cuando se habla de revistas literarias y de redes, difícilmente puede haber un caso que evoque tan plenamente esas dos nociones como es el de Casa de las Américas [...]” (129). A continuación, Gilman subraya que la revista tiene poder, al punto de ser el mecanismo a partir del cual se "busca eduacr al soberano en materia artísitica explicando el progreso de las formas hacia estéticas no figurativas" (134).

No obstante ello, las revistas no sólo son significativas en sí mismas, puesto que las demás publicaciones, ya sean contemporáneas, anteriores o posteriores, se mencionan entre sí, ya sea criticándose, felicitándose o anunciándose. Estos elementos, ayudan también en la construcción de estas redes, generadas a partir del juego escritural que estos hechos de cultura entablan. Esto último se entiende al leer el artículo de Manuela Luengas, titulado "La revista Mito (Colombia 1955-1962): el ensayo de las libertades", donde explica lo siguiente:

[...] ¿Por qué hablar de ensayos y revistas en un mismo plano? Lo que esto supone, o lo que pretendo proponer, es que hay un vínculo epistemológico entre ensayos y revistas que, aunque albergan un abismo de diferencias entre las dos, están hermanadas por un tipo específico de actividad intelectual, de carácter altamente reflexiva e ideológica, de un proceso del pensar y definir el mundo que habita hondamente en las dos [...] Así, si se entiende al ensayo como un género complejo que inscribe o reproduce discursos dialógicos y colectivos, pero más allá, que moviliza ideas [...] 
se puede proponer la existencia de similitudes y diálogos enriquecedores entre este género y el de las revistas culturales. (265)

Entablar un lazo social entre revistas implica la instalación y la búsqueda de la legitimación respecto a las demás En este sentido, las revistas como conjunto de enunciados, debe reunir una cierta cantidad de condiciones para ser aceptada dentro del conjunto específico de enunciados entre los cuales intenta validarse. Esto tiene relación con la configuración de relatos de la que estas publicaciones participan, donde proponer un nuevo enunciado, ya sea al filo de las reglas o proponiendo un cambio de éstas, indefectiblemente las lleva a situarse.

Según afirma Daphne de Marneffe (2007), "la revista es en relación a lo que han hablado y hablan de ella (una filiación intertextual)" (s/p). Acorde a lo anterior, estos periódicos efectivamente mantienen operaciones transtextuales, en tanto que guardan lazos de cooperación discursiva, no sólo porque sus discursos fundacionales o performance inaugurales sean similares respecto de sus propuestas, sino también porque los escritores que participaron de ellas no son exclusivos de una revista, sino que trabajan bajo el principio de "colaboración conjunta" que incluye a directores y columnistas.

Por lo tanto, estudiar las relaciones de "red" entre las revistas es complejo, pues involucra revisar la permanente reconfiguración a la cual las revistas, en su particularidad, están siendo sometidas. Pero al plantearse esta problemática para su estudio, implica acentuar la independencia que éstas alcanzan estando ya inmersas dentro del campo, pues "otros", que no serán precisamente sus propios productores hablarán de ella, para bien o para mal, pero al hacerlo significa que la están considerando como "una más" dentro del juego del espacio de tomas de posición. Nelly Richard en su artículo "Escrituras minoritarias y revistas culturales independientes" en donde profundiza el proyecto de la Revista de Crítica Cultural, comenta que 
El registro bajo el cual la revista eligió inscribir su proyecto fue el de la "crítica cultural”. ¿Qué significaba optar por este registro, al menos para mí, a comienzos de los ochenta en Chile? El registro de la crítica cultural tenía que ver, primero, con una demarcación estratégica que buscaba separarse de dos estados de lengua dominantes en el campo de los saberes legitimados y acreditados: por un lado, la lengua de los estudios culturales latinoamericanos de la academia norteamericana y, por otro, la lengua de la sociología de la transición convertida en Chile en una lengua experta que iba destinada a gobernar las relaciones entre democracia y mercado.

En el primer caso, la Revista de Crítica Cultural les ofreció sus páginas a varios intercambios Norte- Sur (de los que participaron Néstor García Canclini, Alberto Moreiras, Idelber Avelar, John Beverley entre otros) [...]. (197)

Respecto a los productores de las revistas, también se genera un vínculo (según mostraba la cita anterior), pues la relación discursiva que generan con los otros agentes involucrados en estos proyectos culturales les vale el reconocimiento entre sus pares. Por lo tanto, la pregunta es si acaso existe "salvación" dentro del campo fuera de las redes de autores. Según Bourdieu (1984), "raro es aquel que escapa a toda afiliación y no se liga por lo menos a un editor o a una revista. Más raro es aún el escritor que lleva adelante su obra y asegura su notoriedad al margen de la red de luchas de competencia" (15).

Finalmente, el Escrituras en tránsito. Revistas y redes culturales en América Latina, es un trabajo imprescindible para todos y todas quienes nos dedicamos con tanta pasión, amor, y a veces mucho pesar, al estudio de las revistas, debido a la gran calidad de los trabajos que lo componen, la coherencia de su propuesta, y las alternativas metodológicas que cada uno de los artículos plantea 
CATEDRAL TOMADA: Revista literaria latinoamericana / Journal of Latin American Literary Criticism Marina Alvarado

para continuar profundizando y enriqueciendo el corpus de investigaciones sobre revistas. 